\title{
Association between social participation and mental health consultation in individuals with suicidal ideation: a cross- sectional study
}

Hin Moi Youn ${ }^{1}$, Soo Hyun Kang ${ }^{1}$, Sung-In Jang ${ }^{2,3^{*}}$ (1) and Eun-Cheol Park ${ }^{2,3}$

\begin{abstract}
Background: Suicidal ideation is a significant public health concern worldwide. Although suicides might be preventable through the provision of adequate treatment, mental health consultation is still mostly underutilized. This study thus aimed to examine the association between social participation and utilization of mental health consultations in individuals with suicidal ideation.

Methods: Data were collected from the nationwide Community Health Survey (conducted by the Korea Centers for Disease Control and Prevention, 2017). A total of 17,067 individuals (men: 32.9\%, women: 67.1\%) who reported experiencing suicidal ideation were included in the analysis. The mean age of the study population was $60.1( \pm 17.8)$ years old. This study examined social participation; the number of social activities participated in among leisure, volunteer, social, and religion related activities. Multivariate logistic regression was then used to assess the significance of these associations.

Results: Among those experienced suicidal ideation, 1860 (10.9\%) reported receiving mental health consultation services (men: 8.8\%, women: 11.9\%). Overall, an increased social participation was significantly associated with increased odds of using forms of mental health consultation ( $\mathrm{OR}=1.65,95 \% \mathrm{Cl}: 1.31-2.09)$.

Conclusions: In this study, significant evidence of the links between social participation and utilization of mental health consultation was discovered among at risk individuals with suicidal ideation. Suicide prevention policies and programs designed to enhance social participation could potentially encourage people at suicide risk to seek the help they need. Further research focusing on social approaches can produce useful information to plan and implement comprehensive and effective strategies.
\end{abstract}

Keywords: Social participation, Mental health consultation, Suicide prevention, Suicide, Suicidal behavior, Suicidal ideation

\footnotetext{
* Correspondence: jangsi@yuhs.ac

${ }^{2}$ Institute of Health Services Research, Yonsei University, Seoul, Republic of

Korea

${ }^{3}$ Department of Preventive Medicine, Yonsei University College of Medicine,

Seoul, Republic of Korea

Full list of author information is available at the end of the article
}

(c) The Author(s). 2020 Open Access This article is licensed under a Creative Commons Attribution 4.0 International License, which permits use, sharing, adaptation, distribution and reproduction in any medium or format, as long as you give appropriate credit to the original author(s) and the source, provide a link to the Creative Commons licence, and indicate if changes were made. The images or other third party material in this article are included in the article's Creative Commons licence, unless indicated otherwise in a credit line to the material. If material is not included in the article's Creative Commons licence and your intended use is not permitted by statutory regulation or exceeds the permitted use, you will need to obtain permission directly from the copyright holder. To view a copy of this licence, visit http://creativecommons.org/licenses/by/4.0/ The Creative Commons Public Domain Dedication waiver (http://creativecommons.org/publicdomain/zero/1.0/) applies to the data made available in this article, unless otherwise stated in a credit line to the data. 


\section{Background}

Suicidal behavior is a global public health concern. Suicides account for $1.4 \%$ of all deaths worldwide, making it the 18th leading cause of death in 2016 [1]. Korea has had one of the highest suicide rates over the last several decades when compared to other members of the Organization for Economic Cooperation and Development (OECD) [2]. As of 2018, the suicide rate in Korea increased by $9.5 \%$, meaning that it was the cause of 26.6 per 100,000 deaths [3].

Suicidal behaviors, including suicidal ideation, plans, and attempts, are strongly predictive of death by suicide. Although suicide prevention requires a comprehensive and multidisciplinary approach, one of the well-known and efficacious interventions in reducing suicide risks is ensuring that people at risk receive appropriate treatment for their mental health problems [4]. However, despite the increased need for professional services, the vast number of people at risk for suicide are not in treatment $[5,6]$. Individuals who fail to receive adequate treatment may experience an escalation of symptoms, such as the progression of depression into suicidal behaviors [7]. Therefore, enhancing engagement in treatment through mental health services may be one of the key strategies in preventing suicidal behaviors and death. As a result, numerous studies have been conducted to better understand helpseeking and mental health service utilization among suicidal individuals and to identify contributing factors that influence individuals' decisions to utilize mental health services [8-10]. These studies have ranged in their scope and focus, and some have been aimed at social factors [11].

Social participation, as well as active engagement in volunteering and religious activities, are found to be associated with better mental and physical health and well-being [12-14]. Furthermore, individuals' pathway into treatment are often influenced by the support provided by their social contacts [15]. However, social participation or other forms of social factors do not always lead to mental health services utilization. Some studies have presented possible effects of social factors on mental health help-seeking behaviors [16-19]. Gourash outlined four hypothetical avenues concerning the interactions between a person's social networks and their mental health service utilization: buffering the experience of stress, therefore obviating the need for help; providing instrumental and emotional support that substitutes for professional assistance; advocating for or referring to services; and transmitting attitudes, values, and norms about the nature of help-seeking behaviors [19].

This study sought to examine the association between social participation, or the social activities that individuals at risk of suicidal behaviors engage in regularly, and their utilization of mental health consultation.

\section{Methods}

\section{Study population}

This study used data from the Korean Community Health Survey (KCHS), a nationwide cross-sectional survey. The KCHS is designed to collect data to plan, implement, monitor, and evaluate community-level health promotion and disease prevention programs by the Korea Centers for Disease Control and Prevention (KCDC). The KCHS has been conducted annually since 2008 by trained interviewers through direct face-to-face interviews, and 253 national public health centers have participated. The survey subjects are aged 19 or older were selected by the probability proportional sampling method and the systematic sampling method. The data consisted of 358 questionnaires regarding sociodemographic characteristics, disease and relevant information, life style, and health behavior information. The KCHS is annually reviewed and approved by the institutional review board of the KCDC, and written informed consent is obtained from all participants. The data is freely accessible online at [http://chs.cdc.go.kr]. In 2017, among 228,381 individuals, $17,450(7.6 \%)$ reported having experienced suicidal ideation only, and 740 (0.3\%) reported having experienced both suicidal ideation and suicide attempt within 1 year. In the study, we included those who had suicidal ideation only. Suicidal ideation was measured by asking whether the subject had thoughts of suicide within the past year [20]. The questions were assessed using "yes" or "no" answers based on the subjects' self-report. Data for any subjects with missing values for other study variables were excluded. In the end, a final sample population of 17,067 who had experienced suicidal ideation within the past year was utilized.

\section{Variables \\ Mental health consultation utilization}

The dependent variable in this study was subjects' use of mental health consultation services regarding their suicidal ideation. Subjects who reported having suicidal ideation within 1 year were asked the following question, "Did you receive any mental health consultation services from a medical institution, professional consulting institution, or local mental health center in regards to your suicidal ideation?" In the study, mental health consultation service use was determined by "yes" or "no" responses.

\section{Social participation}

The main independent variable of interest in this study is social participation. Social participation was determined as the number of social activities in which a subject participated within 1 year. Options included leisure, voluntary, religious, and social gatherings. Participants could respond with no activities (0), one activity (1), two activities (2), and more than three activities (3). The study also measured the frequency of social contact with family, neighbors, and friends (less than once per week, more than once per week). 


\section{Demographic characteristics and health status}

Covariates regarding participants' demographic characteristics included their sex, age (grouped as 19-29 years, 29-39 years, 40-49 years, 50-59 years, 60-69 years, 70-79 years, or $\geq 80$ years), education level ( $\leq$ middle school graduate, high school graduate, college graduate, or $\geq$ university graduate), occupation (unemployed/housewives/soldiers/ students, low-skilled blue collar, high-skilled blue collar, low-skilled white collar, or high-skilled white collar), marital status (no spouse or with spouse), household income $(\leq 1$ million won/month, 1-2 million won/month, 2-3 million won/month, 3-4 million won/month, or $\geq 4$ million won/ month), number of household members $(1,2$, or $\geq 3)$, region (rural, urban, or metropolitan), and basic livelihood security recipient status (yes or no). Health-related covariates included the presence of depressive symptoms (yes or no), perceived health status (unhealthy, average, or healthy), difficulties in daily routine activities (yes or no), currently smoking (yes or no), and high risk drinking (yes or no). The study also included main reasons for suicidal ideation (physical problems such as illnesses or disability, financial difficulties, loneliness, domestic troubles, difficulties at work, or others such as problems with romantic relationships and concerns about career building).

\section{Statistical analysis}

All analyses included the use of weighted variables. Descriptive analysis was conducted first, followed by logistic regression analysis, to determine the odds ratios (ORs) and confidence intervals (95\% CIs) using "proc survey logistic." For the logistic regression analysis, the association between social participation and mental health consultation was assessed for those who experienced suicidal ideation. Statistical analyses were performed using SAS software version 9.4 (SAS Institute, Cary, NC, USA).

\section{Results}

The general characteristics of the study population are summarized in Table 1. Among the 17,067 individuals in the study population, $1860(10.9 \%)$ received mental health consultation, whereas 15,207 (89.1\%) did not. More than half of individuals (56.0\%) participated regularly in one or more social activities, while $44 \%$ did not participate in any social activities. Of those who reported participation in at least one social activity, $11.6 \%$ received mental health consultation for their suicidal thoughts, whereas $10.0 \%$ of those who did not have any social participation received mental health consultation. Individuals had social contact more than once a week with family (54.6\%), friends (43.1\%), and neighbors (57.3\%). In total, physical health problems such as illness or disabilities accounted for $30.7 \%$, followed by financial difficulties (17.2\%), other reasons (17.2\%), loneliness (15.2\%), and domestic troubles (14.2\%). In the study, more women (67.1\%) reported experiencing suicidal ideation than men $(32.9 \%)$, and the proportion of mental health consultation use was slightly higher in women (11.9\%) than men $(8.8 \%)$ as well. Table 2 shows the results of logistic regression analyzing the association between social participation and mental health consultation. The results showed that increased numbers of social activities were significantly associated with increased odds of using mental health consultation. Those who participated in more than three social activities had the highest odds for using mental health consultation $(\mathrm{OR}=1.67,95 \% \mathrm{CI}: 1.20-2.32)$ compared to individuals with no social participation. The frequency of social contact with family, friends, or neighbors did not show a significant effect. Individuals who thought about suicide due to financial difficulties were the least likely to use mental health consultation $(\mathrm{OR}=0.65$, 95\% CI: $0.52-$ 0.80 ), and individuals whose main reason for suicidal ideation was domestic troubles were the most likely to use mental health consultations $(\mathrm{OR}=1.36,95 \% \mathrm{CI}$ : 1.11-1.68). Table 3 shows the analysis results regarding the association between social participation and mental health consultation according to types of social activities. Individuals who participated in leisure/sports $(\mathrm{OR}=1.47$, 95\% CI: $1.25-1.73)$ and religion $(\mathrm{OR}=1.17,95 \% \mathrm{CI}$ : 1.02-1.33) related activities showed significantly higher odds of using mental health services compared to those with no social participation. Figure 1 presents the results for the subgroup analysis of the association between social participation and mental health consultation, stratified by the main reasons for having suicidal ideation. The analysis reveals that respondents whose reasons were related to physical health problems such as illness or disabilities showed a graded positive association (more than three: $\mathrm{OR}=2.16,95 \% \mathrm{CI}: 1.36-3.44$ ).

\section{Discussion}

The study highlighted the link between social participation and the use of mental health consultation among individuals with suicidal ideation. There are increasing public concerns regarding mental health in Korea, yet many people are reluctant to use any form of mental health consultation services. Among various contributing factors, we attempted to focus on social participation and found that it was significantly related to the use of mental health consultation. Although a number of studies have demonstrated that social participation has beneficial health effects, inconsistent patterns have been found regarding its association with mental health consultation or service use. Some studies suggested that social participation acted as a substitute for the benefits of mental health services, thereby reducing the utilization of professional services [19]. Some studies found that social participation facilitated the utilization of professional 
Table 1 General characteristics of the study population

Variables

Mental health consultation

\begin{tabular}{ll}
\hline Total & \%
\end{tabular}

17,067

100.0

1860

10.9

0.9

\section{1}

5905

2741

910

44.0

Frequency of social contact with family

Less than once/w

More than once/w

\section{4}

9323

$$
45.4
$$

10.0

$\frac{N}{N}$

15,207

Frequency of social contact with friends

Less than once/w

More than once/w

9710

7357

$$
56.9
$$

Frequency of social contact with neighbor

Less than once/w

More than once/w

7291

9776

$$
42.7
$$

Reasons for suicidal ideation

Illness or disability

Financial difficulties

Loneliness

Domestic troubles

Troubles at work

Others

Sex

$$
\text { Male }
$$$$
\text { Female }
$$

Age

$19-29$
$29-39$
$40-49$
$50-59$
$60-69$
$70 \sim 79$
$\geq 80$

Educational level

None/Middle school graduate

High school graduate

College graduate

University graduate/higher

\section{Occupation}

Others $^{b}$

Low-skilled blue collar

High-skilled blue collar
5236

2928

2594

2418

961

2930

5611

11,456

1138

1503

2121

2934

3149

3805

2417

9389

4190

1165

2323

9142

2627

1965
34.6

16.1

5.3

54.6

869

991

753

647

324

136

10.0

11.0

11.8

14.9

43.1

57.3

923

937

1031

829

30.7

17.2

15.2

14.2

5.6

17.2

32.9

67.1

6.7

8.8

12.4

17.2

18.5

22.3

14.2

55.0

24.6

6.8

13.6

500

253

312

332

117

346

496

1364

11.2

10.6

6758

5258

2417

774

6875

8332

10.6

8679

6528

11.3

12.7

6368

8839

9.6

4736

4736

2675

2282

2085

844

2584

11.8

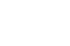

8.8

5115

10,092

11.9

.

19.2

919

1277

1826

2583

2771

3504

2327

3.7

232

8590

3633

1029

1955

368

11.7

15.8

53.6

15.4

11.5

1061

11.6

8081

2383

1816
9.3

7.6
0.5935

88.8

89.4

89.4

88.7

87.3

90.4

90.0

89.0

88.2

85.1

8

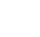

0.2882

0.0037

$<.0001$

90.5

91.4

88.0

86.2

87.8

88.2

$<.0001$

91.2

88.1

80.8

85.0

86.1

88.0

88.0

92.1

96.3

91.5

86.7

88.3

84.2

$<.0001$ $<.0001$

$<.0001$
88.4

90.7

92.4 
Table 1 General characteristics of the study population (Continued)

\begin{tabular}{|c|c|c|c|c|c|c|c|}
\hline \multirow[t]{4}{*}{ Variables } & \multicolumn{7}{|c|}{ Mental health consultation } \\
\hline & \multicolumn{2}{|l|}{ Total } & \multicolumn{2}{|l|}{ Yes } & \multicolumn{2}{|l|}{ No } & \multirow[t]{3}{*}{$P$} \\
\hline & N & $\%$ & $\mathrm{~N}$ & $\%$ & N & $\%$ & \\
\hline & 17,067 & 100.0 & 1860 & 10.9 & 15,207 & 89.1 & \\
\hline Low-skilled white collar & 1727 & 10.1 & 197 & 11.4 & 1530 & 88.6 & \\
\hline High-skilled white collar & 1606 & 9.4 & 209 & 13.0 & 1397 & 87.0 & \\
\hline Marital status & & & & & & & 0.0002 \\
\hline W/o spouse & 7388 & 43.3 & 848 & 11.5 & 6540 & 88.5 & \\
\hline With spouse & 9679 & 56.7 & 1012 & 10.5 & 8667 & 89.5 & \\
\hline Number of household members & & & & & & & 0.4388 \\
\hline 1 & 4208 & 24.7 & 400 & 9.5 & 3808 & 90.5 & \\
\hline 2 & 6520 & 38.2 & 706 & 10.8 & 5814 & 89.2 & \\
\hline$\geq 3$ & 6339 & 37.1 & 754 & 11.9 & 5585 & 88.1 & \\
\hline Region & & & & & & & $<.0001$ \\
\hline Rural & 6018 & 35.3 & 499 & 8.3 & 5519 & 91.7 & \\
\hline Urban & 6718 & 39.4 & 779 & 11.6 & 5939 & 88.4 & \\
\hline Metropolitan & 4331 & 25.4 & 582 & 13.4 & 3749 & 86.6 & \\
\hline Household Income & & & & & & & 0.6977 \\
\hline Less than 1 million won/m & 6821 & 40.0 & 658 & 9.6 & 6163 & 90.4 & \\
\hline 1-2 mil won/m & 3071 & 18.0 & 340 & 11.1 & 2731 & 88.9 & \\
\hline 2-3 mil won/m & 2509 & 14.7 & 301 & 12.0 & 2208 & 88.0 & \\
\hline 3-4 mil won/m & 1776 & 10.4 & 198 & 11.1 & 1578 & 88.9 & \\
\hline Over 4 mil won/m & 2890 & 16.9 & 363 & 12.6 & 2527 & 87.4 & \\
\hline Basic livelihood security recipient & & & & & & & $<.0001$ \\
\hline Yes & 1618 & 9.5 & 271 & 16.7 & 1347 & 83.3 & \\
\hline No & 15,449 & 90.5 & 1589 & 10.3 & 13,860 & 89.7 & \\
\hline Depressive symptoms & & & & & & & $<.0001$ \\
\hline Yes & 6216 & 36.4 & 1191 & 19.2 & 5025 & 80.8 & \\
\hline No & 10,851 & 63.6 & 669 & 6.2 & 10,182 & 93.8 & \\
\hline Perceived health status & & & & & & & $<.0001$ \\
\hline Unhealthy & 8701 & 51.0 & 1012 & 11.6 & 7689 & 88.4 & \\
\hline Average & 5823 & 34.1 & 612 & 10.5 & 5211 & 89.5 & \\
\hline Healthy & 2543 & 14.9 & 236 & 9.3 & 2307 & 90.7 & \\
\hline Difficulty in daily activity & & & & & & & 0.4020 \\
\hline Yes & 6078 & 35.6 & 605 & 10.0 & 5473 & 90.0 & \\
\hline No & 10,989 & 64.4 & 1255 & 11.4 & 9734 & 88.6 & \\
\hline Currently Smoking & & & & & & & 0.7938 \\
\hline Yes & 3026 & 17.7 & 344 & 11.4 & 2682 & 88.6 & \\
\hline No & 14,041 & 82.3 & 1516 & 10.8 & 12,525 & 89.2 & \\
\hline High risk drinking & & & & & & & 0.0871 \\
\hline Yes & 1814 & 10.6 & 175 & 9.6 & 1639 & 90.4 & \\
\hline No & 15,253 & 89.4 & 1685 & 11.0 & 13,568 & 89.0 & \\
\hline
\end{tabular}

${ }^{a}$ Number of social activities a respondent is currently participated in among religion, social, leisure and volunteer activities

${ }^{\mathrm{b}}$ Others include housewives, students, soldiers and unemployed 
Table 2 Logistic regression analysis to investigate the association between social participation and mental health consultation

\begin{tabular}{|c|c|c|c|c|c|}
\hline \multirow[t]{2}{*}{ Variables } & \multicolumn{5}{|c|}{ Mental health consultation } \\
\hline & $\mathrm{OR}$ & $95 \% \mathrm{Cl}$ & & & $P$ \\
\hline \multicolumn{6}{|c|}{ No. of social participation ${ }^{a}$} \\
\hline 0 & 1.00 & & & & \\
\hline 1 & 1.22 & $(1.07$ & - & 1.40) & 0.2305 \\
\hline 2 & 1.41 & $(1.18$ & - & 1.68) & 0.2276 \\
\hline$\geq 3$ & 1.67 & $(1.31$ & - & 2.13) & 0.0048 \\
\hline \multicolumn{6}{|c|}{ Frequency of social contact with family } \\
\hline Less than once/w & 1.00 & & & & \\
\hline More than once/w & 1.12 & $(0.99$ & - & 1.27) & 0.0650 \\
\hline \multicolumn{6}{|c|}{ Frequency of social contact with friends } \\
\hline Less than once/w & 1.00 & & & & \\
\hline More than once/w & 0.94 & $(0.83$ & - & 1.08) & $\begin{array}{l}0.11 \\
3806\end{array}$ \\
\hline
\end{tabular}

Frequency of social contact with neighbor

Less than once/w

More than once/w

1.00

0.98

$(0.87$

1.11)

0.7673

\section{Reasons for suicidal ideation}

Illness or disability

Financial difficulties

Loneliness

Domestic troubles

Troubles at work

Others

Sex

Male

Female

Age

19-29

29-39

40-49

50-59

60-69

$70 \sim 79$

$\geq 80$

\section{Educational level}

None/Middle school graduate

High school graduate

College graduate

University graduate/higher

\section{Occupation}

Others $^{b}$

Low-skilled blue collar

High-skilled blue collar

Low-skilled white collar
1.00

0.65

$(0.52$

(0.95

$(1.11$

1.36

1.01

0.99

1.00

1.20

1.00

0.89

0.84

0.49

0.50

0.32

0.16

1.00

1.18

0.92

1.23

1.00

0.69

1.04

0.78
$(1.03$

$(0.71$

$(0.66$

(0.38

(0.38

$(0.23$

(0.11

$(1.00$

$(0.70$

(0.98

$(0.57$

(0.82

(0.63
0.80)

1.44)

1.68)

1.33)

1.21)

1.41)

0.0206

$<.0001$

$<.0001$

0.5858

0.7734

$<.0001$

$<.0001$

0.23)

1.40)

0.0934

0.0682

0.035

1.54)

0.83)

0.0035

0.0409

0.2352 
Table 2 Logistic regression analysis to investigate the association between social participation and mental health consultation (Continued)

\begin{tabular}{|c|c|c|c|c|c|}
\hline \multirow{3}{*}{$\begin{array}{l}\text { Variables } \\
\text { High-skilled white collar }\end{array}$} & \multicolumn{5}{|c|}{ Mental health consultation } \\
\hline & \multirow{2}{*}{$\begin{array}{l}\mathrm{OR} \\
0.81\end{array}$} & \multicolumn{3}{|c|}{$95 \% \mathrm{Cl}$} & \multirow{2}{*}{$\begin{array}{l}P \\
0.5467\end{array}$} \\
\hline & & $(0.65$ & - & 1.00) & \\
\hline \multicolumn{6}{|l|}{ Marital status } \\
\hline W/o spouse & 1.00 & & & & \\
\hline With spouse & 0.86 & $(0.73$ & - & 1.01) & 0.0599 \\
\hline \multicolumn{6}{|c|}{ Number of household members } \\
\hline 1 & 1.00 & & & & \\
\hline 2 & 1.21 & $(1.00$ & - & 1.46) & 0.0162 \\
\hline$\geq 3$ & 1.05 & $(0.85$ & - & 1.30) & 0.5762 \\
\hline
\end{tabular}

Region

Rural $\quad 1.00$

$\begin{array}{ll}\text { Urban } & 1.23\end{array}$

$1.23 \quad(1.06$

$\left.\begin{array}{llll}1.06 & - & 1.43\end{array}\right) \quad 0.1228$

Metropolitan

1.27

$(1.08$

1.50)

0.0328

\section{Household Income}

Less than 1 million won/m

1-2 mil won/m

$3-4 \mathrm{mil}$ won/m

Over 4 mil won/m

Basic livelihood security recipient

Depressive symptoms

Yes

Perceived health status

Unhealthy

Average

1.00

Healthy

Difficulty in daily activity

Yes

No

High risk drinking

Yes

1.00

1.20

No
$(0.56$

$(0.44$

0.75)

0.2861

$0.65)$

$O R$ refers to odds ratio, $95 \% \mathrm{Cl}$ refers to confidence interval

a Number of social activities a respondent is currently participated in among religion, social, leisure and volunteer activities

${ }^{\mathrm{b}}$ Others include housewives, students, soldiers and unemployed 
Table 3 Association between social participation and mental health consultation according to types of social activity

\begin{tabular}{llllll}
\hline Variables & \multicolumn{4}{l}{ Mental health consultation } \\
\cline { 2 - 6 } & OR & $95 \% \mathrm{Cl}$ & & $\boldsymbol{P}$ \\
\hline Types of social activity & & & & & \\
Leisure/sports (ref = no) & 1.47 & $(1.25$ & - & $1.73)$ & $<.0001$ \\
Voluntary (ref = no) & 1.13 & $(0.88$ & - & $1.45)$ & 0.3306 \\
Religion (ref = no) & 1.17 & $(1.02$ & - & $1.33)$ & 0.0119 \\
Social (ref = no) & 0.99 & $(0.86$ & - & $1.15)$ & 0.9385 \\
\hline
\end{tabular}

$O R$ refers to odds ratio, and $95 \% \mathrm{Cl}$ refers to confidence interval

services through advocacy or by decreasing any associated stigma and encouraging service use [17, 21-23].

In our study, participating in a higher number of social activities was positively and significantly associated with increased odds of utilizing mental health consultation services. Social participation has a role in both facilitating and nurturing interpersonal ties because they are carried out in the company of others [24] and thereby provide people with interactions with socially significant others [25]. Hence, these activities encompass all the beneficial components of social participation [24]. Of the four types of social activities, the association with religion led to utilization of mental health services among people who experienced suicidal ideation. Religious beliefs and participation in related activities are wellknown determinants of mental health service utilization
[26-28]. Whether or not religion has a positive or negative association, however, varies depending on an individual's personal characteristics, such as the severity of any mental health problems, age, and community-level factors, such as the role of fellow community members.

Overall, social participation helps people to build supportive and trusting relationships, as well as a sense of communal integration, which are all necessary in developing beneficial social participation. In this study, we also included the frequency of contact, which is one measure to assess social networks. Our findings indicated that a person having more frequent contact with family may have more positive influences on mental health consultation than contact with neighbors or friends, although there was only a marginal significance. Earlier studies have found that various types of social networks may be qualitatively different and, therefore, have differential effects on a person in terms of their family, relatives, friends, and neighbors [18, 21, 22]. They suggested that family and relatives could have a more positive referral function on a person's use of professional mental health services, as well as lowering the social stigmas associated with those services. In addition, living with a spouse increased the odds of utilizing services, which may also reflect the positive association of social support. Social networks with friends could be interpreted as providing relatively low social support when compared to family and, by extension, have fewer

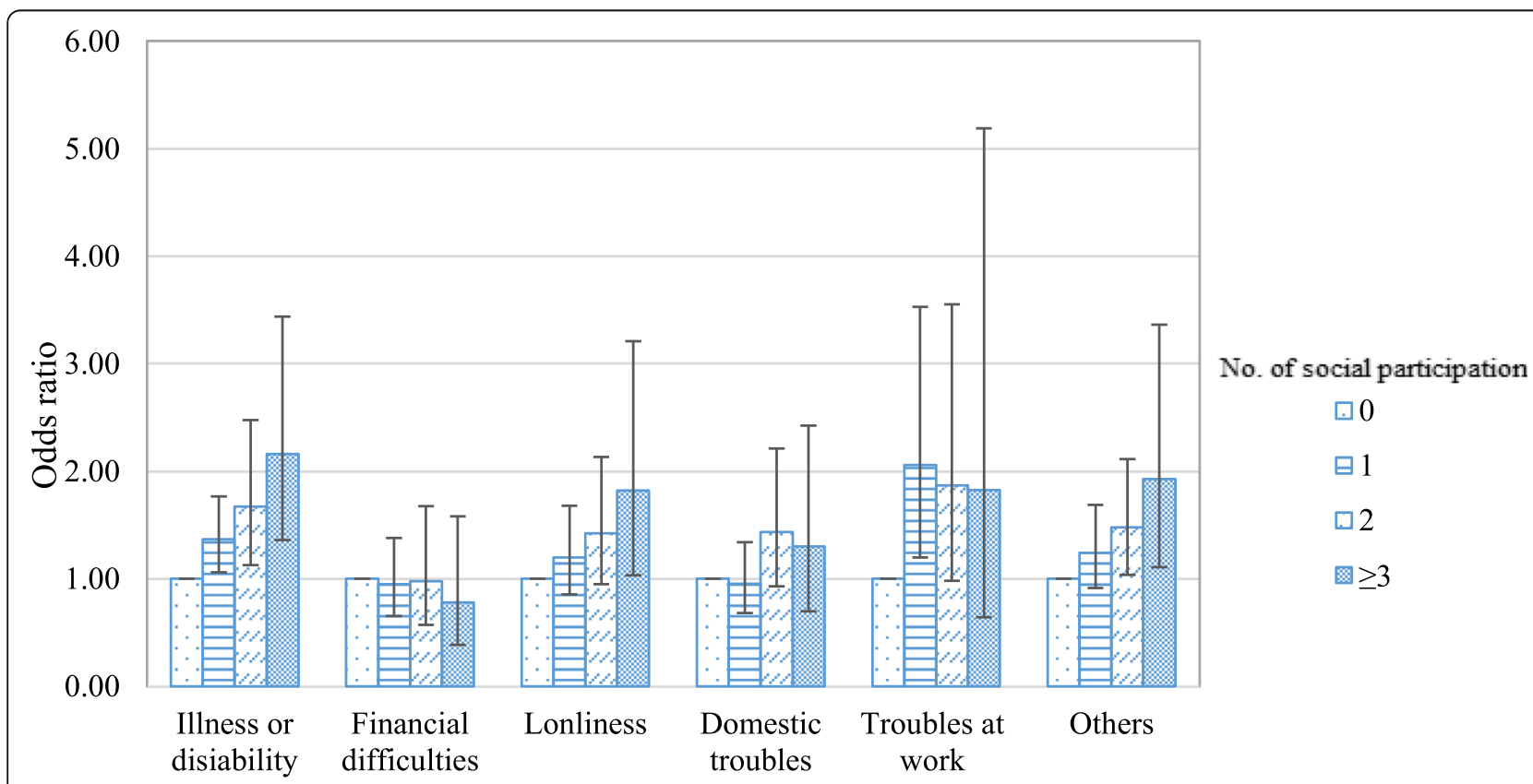

Reasons for suicidal ideation

Fig. 1 Subgroup analysis of mental health consultation according to number of social pariticipation stratified by reasons for suicidal ideation 
effects on respondents' behaviors. Conversely, social contact with friends was found to possess a stressreduction function and was therefore associated with reduced service utilization. Some studies suggested that, although social networks with friends may constitute comparatively weaker ties, they may still result in sharing of information about multiple services [29], which could then increase the use of alternative forms of healthcare interventions.

Regarding the reasons why respondents had suicidal ideation, those who thought of suicide due to financial difficulties were the least likely to use mental health consultation. Financial difficulties can have a severely negative impact of mental health and are a major risk factor that can lead to suicide. Since the main source of the problem is economical rather than clinical, they might have less need for professional consultations. Furthermore, they may experience greater unmet needs of mental health services due to a lack of affordability. Therefore, it is imperative that prevention strategies for those having financial problems should be differentiated from clinical approaches, for example, like providing welfare support or reducing unemployment [30].

In this study, we observed other covariates associated with mental health consultation. Depressive symptoms are a primary risk factor for suicidal behaviors and are also the strongest predictor of mental healthcare service utilization [31]. Our findings showed that men were less likely to use mental health services than women, which are consistent with the findings of previous studies on mental healthcare utilization [32, 33]. It is known that men and women have different help-seeking behaviors for a range of mental health issues [33, 34]. It then also becomes important to examine the potential differential effects of social networks on the help-seeking behaviors of women versus men. Alternatively, men and women may place different emphases on the importance of the beliefs and values of their respective social networks [34]. Additionally, our findings on consultation utilization due to suicidal ideation have been comparable to other studies and shown that older people who experience suicidal ideation are less likely to seek mental health treatment $[33,35,36]$.

While the present study provides insight on the role of individuals' social participation in relation to mental health consultation, the findings should be interpreted with caution owing to several limitations. First, this is a cross-sectional study, meaning that causality between two events cannot be distinguished. Social participation may buffer the experience of mental health problems, resulting in a decreased need for professional help [23]. In addition, it did not capture any changes in social participation and how those changes could be associated with the use of mental health consultation. Furthermore, the study did not assess whether an individual was participating in social activities at or around the time as their experience of suicidal ideation. An understanding of times frames for each variable would help gauge the extent to which retrospective recall biases may have operated. Future research with assessment for time frames and dynamics of social participation and how they are associated with suicidal ideation and mental health service use would provide a better understanding of behaviors of those who are at risk of suicide. Second, the use of mental health consultation and suicidal ideation were measured based on individuals' self-report, and this could introduce recall bias of information in the study. Third, this study accounted for the quantitative aspect of social participation. Qualitative measures, including perceived social support, level of intimacy, and intensity were not assessed. In addition, this study did not distinguish between various types of mental health consultations. The effects of social participation may vary according to the types of services, such as general medical services, specialty psychiatric services, or other forms of services.

Despite these limitations, this study has several strengths. It involved a large, well-validated dataset collected from a nationally representative sample of the South Korean population. The study offers an understanding of social factors that are associated with mental health consultation.

\section{Conclusions}

This study presented evidence of the links between social participation and mental health consultation in those with suicidal ideation. Based on the findings, the study suggests future investigation on the role of social capital such as participation, network, connectedness, and support and their various outcomes, especially in terms of the more subjective and qualitative concept of perceived support. Mental health and its related behaviors are complicated. Research from a social point of view will certainly widen the understanding of the dynamics of individuals' mental health and related behaviors. Suicide prevention policies and programs designed to enhance social participation could potentially encourage people at risk of suicide to seek the help they need. Such evidence on social approaches can produce useful information to plan and implement comprehensive and effective strategies.

\section{Abbreviations}

OECD: Organization for Economic Co-operation and Development; KCHS: Korean Community Health Survey; KCDC: Korean Center for Disease Control and Prevention

\section{Acknowledgements}

We offer our appreciation to the Korean Centers for Disease Control (KCDC) for providing meaningful data.

Authors' contributions

HMY contributed to study concept and design, data analysis, drafting the manuscript, interpretation, and critical revision of article. SHK contributed to 
study concept and data interpretation. SIJ and ECP directed and reviewed the study and provided important intellectual content. All authors read and approved the final manuscript.

\section{Funding}

This study was supported by a faculty research grand of Yonsei University College of Medicine (6-2018-0174 and 6-2017-0157).

\section{Availability of data and materials}

The datasets generated and/or analyzed during the current study are available in the CHS website. (http://chs.cdc.go.kr).

\section{Ethics approval and consent to participate}

The Community Health survey received consent from study participants. Instruments and study processes used for the study were approved by the Korea Centers for Disease and Control and Prevention Institutional Review Board and all participants provided voluntary written informed consent.

\section{Consent for publication}

Not applicable.

\section{Competing interests}

The authors declare that they have no competing interests.

\section{Author details}

'Department of Public Health, Graduate School, Yonsei University, Seoul, Republic of Korea. ${ }^{2}$ Institute of Health Services Research, Yonsei University, Seoul, Republic of Korea. ${ }^{3}$ Department of Preventive Medicine, Yonsei University College of Medicine, Seoul, Republic of Korea.

Received: 15 December 2019 Accepted: 9 June 2020

Published online: 16 June 2020

\section{References}

1. World Health Organization. Suicide data. 2016.

2. Organisation for Economic Co-operation and Development. Health at glance 2019. 2019.

3. Statistics Korea. 2018 Causes of death statistics. 2019

4. Kapur N. Health services and suicide prevention. J Ment Health. 2009;18:1-5.

5. Lisa M, Peter H. Help-seeking for suicidal thoughts and self-harm in young people: a systematic review. Suicide Life Threat Behav. 2012;42:507-24.

6. Melanie $\mathrm{A}$, lan $\mathrm{H}$, Thomas E. Evaluating factors and interventions that influence help-seeking and mental health service utilization among suicidal individuals: a review of the literature. Clin Psychol Rev. 2015;40:28-39.

7. Joe S, Baser RS, Neighbors HW, Caldwell CH, Jackson JS. 12-month and lifetime prevalence of suicide attempts among black adolescents in the National Survey of American Life. J Am Acad Child Adolesc Psychiatry. 2009; 48:271-82.

8. Pescosolido B, Boyer C. How do people come to use mental health services? Current knowledge and changing perspectives. In: A handbook for the study of mental health: social contexts, theories, and systems. New York: Cambridge University Press; 1999. p. 392-411.

9. Andersen R. Revisiting the behavioral model and access to medical care: does it matter? J Health Soc Behav. 1995;36:1-10.

10. Roberts T, Miguel Esponda G, Krupchanka D, Shidhaye R, Patel V, Rathod S. Factors associated with health service utilisation for common mental disorders: a systematic review. BMC Psychiatry. 2018;18:262.

11. Litwin H. Social networks and well-being: a comparison of older people in Mediterranean and non-Mediterranean countries. J Gerontol Soc Sci. 2010; 65(B):599-608.

12. Phillps D. Mental health status, social participation, and happiness. J Health Soc Behav. 1967;8:285-91.

13. Daisuke T, Katsunori K, Ichiro K. Social participation and mental health: moderating effects of gender, social role and rurality. BMC Public Health. 2013;13:701.

14. Glass TA, De Leon CM, Marottoli RA, Berkman LF. Population based study of social and productive activities as predictors of survival among elderly Americans. BMJ. 1999;319:478-83..

15. Pescosolido BA. Beyond rational choice: the social dynamics of how people seek help. Am J Sociol. 1992;97:1096-138.
16. Vogel DL, Wade NG, Wester SR, Larson L, Hackler AH. Seeking help from a mental health professional: the influence of one's social network. J Clin Psychol. 2007;63:233-45.

17. Maulik PK, Eaton WW, Bradshaw CP. The role of social network and support in mental health service use: findings from the Baltimore ECA study. Psychiatr Serv. 2009;60:1222-9.

18. MMaulik PK, Eaton WW, Bradshaw CP. The effect of social network and social support on mental health services use, following a life event, among the Baltimore epidemiologic catchment area cohort. J Behav Health Serv Res. 2011;38:29-50.

19. Gourash N. Help-seeking: a review of the literature. Am J Community Psychol. 1978;6:413-23.

20. Korea Center for Disease Control and Prevention. Community health survey 2017: user guide. 2017

21. Lasebikan VO, Owoage ET, Asuzu MC. Social network as a determinant of pathway to mental health service uilization among psychotic patients in a Nigerian hospital. Ann Afr Med. 2012;11(1):12-20.

22. Kang S, Wallace N, Hyun J, Morris A, Coffman J, Bloom J. Social networks and their relationship to mental health service use and expenditures among Medicaid beneficiaries. Psychiatr Serv. 2007;58:689-95.

23. Albert M, Becker T, Mccrone P, Thornicroft G. Social networks and mental health service utilisation - a literature review. Int J Soc Psychiatry. 1998;44. 248-66.

24. Litwin H, Stoeckel K. Social network, activity participation, and cognition:a complex relationship. Res Aging. 2016;38:76-97.

25. Levasseur M, Richard L, Gauvin L, Raymond E. Inventory and analysis of definitions of social participation found in the aging literature: proposed taxonomy of social activities. Soc Sci Med. 2010;71:2141-9.

26. Harris KM, Edlund MJ, Larson SL. Religious involvement and the use of mental health care. Health Serv Res. 2006:41:395-410.

27. Ng TP, Nyunt MSZ, Chiam PC, Kua EH. Religion, health beliefs and the use of mental health services by the elderly. Aging Ment Health. 2011;15:143-9.

28. Bullock M, Nadeau L, Renaud J. Spirituality and religion in youth suicide attmpters' trajectories of mental health service utilization: the year before a suicide attempt. J Can Acad Child Adolesc Psychiatry. 2012;12:186-93.

29. Granovetter M. The strength of weak ties. Am J Sociol. 1973;78:1360-80.

30. Christodoulou N, Christodoulou G. Financial crises: impact on mental health and suggested responses. Psychother Psychosom. 2013;82:279-84.

31. Graham A, Hasking P, Brooker J, Clarke D, Meadows G. Mental health service use among those with depression: an exploration using Andersen's behavioral model of health service use. J Affect Disord. 2017;208:170-6.

32. Kim JL, Cho J, Park S, Park EC. Depression symptom and professional mental health service use. BMC Psychiatry. 2015;15:261.

33. Olfson M, Klerman GL. Depressive symptoms and mental health service utilization in a community sample. Soc Psychiatry Psychiatr Epidemiol. 1992; 27:161-7.

34. Linsey MA, Barksdale CL, Lambert SF, lalongo NS. Socal network influences on service use among urban, African American youth with mental health problems. J Adolesc Health. 2010;47:367-73.

35. Garido M, Kane R, Kass M, Kane R. Use of mental health care by communitydwelling older adults. J Am Geriatr Soc. 2011;59:50-6.

36. Han B, Gfroerer J, Colpe L, Barker P, Colliver J. Serious psychological distress and mental heatlh service use among community-dwelling older USD adults. Psychiatr Serv. 2011;62:291-8.

\section{Publisher's Note}

Springer Nature remains neutral with regard to jurisdictional claims in published maps and institutional affiliations. 